\title{
Temperature response of soil respiration is dependent on concentration of readily decomposable $\mathrm{C}$
}

\author{
A. A. Larionova, I. V. Yevdokimov, and S. S. Bykhovets \\ Institute of Physicochemical and Biological Problems in Soil Science, RAS, 142290, Institutskaya 2, Pushchino, Moscow \\ Region, Russia
}

Received: 16 May 2007 - Published in Biogeosciences Discuss.: 26 June 2007

Revised: 25 September 2007 - Accepted: 13 November 2007 - Published: 4 December 2007

\begin{abstract}
Temperature acclimation of soil organic matter (SOM) decomposition is one of the major uncertainties in predicting soil $\mathrm{CO}_{2}$ efflux associated with the increase in global mean temperature. A reasonable explanation for an apparent acclimation proposed by Davidson and colleagues (2006) based on Michaelis-Menten kinetics suggests that temperature sensitivity decreases when both maximal activity of respiratory enzymes $\left(\mathrm{V}_{\max }\right)$ and half-saturation constant $\left(K_{S}\right)$ cancel each other upon temperature increase. We tested the hypothesis of the canceling effect by the mathematical simulation of data obtained in incubation experiments with forest and arable soils. Our data support the hypothesis and suggest that concentration of readily decomposable $\mathrm{C}$ substrate (as glucose equivalents) and temperature dependent substrate release are the important factors controlling temperature sensitivity of soil respiration. The highest temperature sensitivity of soil respiration was observed when substrate release was temperature dependent and $\mathrm{C}$ substrate concentration was much lower than $K_{s}$. Increase of substrate content to the half-saturation constant by glucose addition resulted in temperature acclimation associated with the canceling effect. Addition of the substrate to the level providing respiration at a maximal rate $\mathrm{V}_{\max }$ leads to the acclimation of the whole microbial community as such. However, growing microbial biomass was more sensitive to the temperature alterations. This study improves our understanding of the instability of temperature sensitivity of soil respiration under field conditions, attributing this phenomenon to changes in concentration of readily decomposable $\mathrm{C}$ substrate.
\end{abstract}

\section{Introduction}

Variations in the temperature sensitivity of soil organic matter (SOM) decomposition are the main source of uncertain-

Correspondence to: I. V. Yevdokimov

(ilyaevd@ rambler.ru) ties in models simulating the $\mathrm{C}$ cycle. It has been suggested that the temperature sensitivity of soil respiration is overestimated in global C cycle models (Thornley and Cannell, 2001). Recently a $Q_{10}$ value of 1.37 was determined by fitting a mechanistic decomposition model to a global data set of SOM (Ise and Moorcroft, 2006), assuming the importance of temperature acclimation of SOM decomposition.

Non-trivial temperature response of soil respiration results from a combination of many temperature dependent processes (Ågren and Wetterstedt, 2007). Vant Hoff's temperature coefficient $\mathrm{Q}_{10}$, which usually varies usually from 2 to 3 , was proposed for the single chemical reaction. Respiration is a process that is more complex in nature, in which many enzymatic reactions are involved. In addition, microbial respiration in soil and other natural environments depends on the rates of decomposition of recalcitrant SOM to C substrates available for microorganisms, substrates and oxygen diffusion and uptake by microbial cells and many other processes.

The theoretical approach recently proposed by Ågren and Wetterstedt (2007) demonstrates a combined effect of three processes: substrate uptake on microbe's surface, substrate diffusion to decomposing organisms and decomposition of recalcitrant SOM to the available substrates. It was shown that the $\mathrm{Q}_{10}$ of two processes which multiply each other is lower than those for individual processes (reactions). When two temperature dependencies cancel each other, the combined process may not even be sensitive to temperature, with the resultant total $\mathrm{Q}_{10} \approx 1$ (Davidson et al., 2006).

A possible explanation for apparent acclimation based on Michaelis-Menten kinetics was proposed by Davidson et al. (2006). Microbial respiration is governed by enzyme kinetics and the activity of respiratory enzymes $(\mathrm{R})$ as dependent on substrate concentration $(\mathrm{C})$ :

$R=\frac{\mathrm{V}_{\max } \times \mathrm{C}}{K_{m}+\mathrm{C}}$

Published by Copernicus Publications on behalf of the European Geosciences Union. 
with the maximal rate of enzyme activity $\mathrm{V}_{\max }$ and halfsaturation constant $K_{m}$. Both $\mathrm{V}_{\max }$ and $K_{m}$ increase with temperature resulting in the canceling effect. Thus, assuming the equal change of $\mathrm{V}_{\max }$ and $K_{m}$, the response of $R$ can be insensitive to temperature, although this suggestion was not confirmed in experiments with soil microorganisms.

A modified Michaelis-Menten equation is used in soil studies mainly for determination of a readily decomposable C substrate as glucose equivalent (Sikora and McCoy, 1990; Bradley and Fyles, 1995; Badalucco and Hopkins, 1997), for partitioning of respiration activity of copiotrophic and oligotrophic components (Panikov et al., 1992), and for evaluation of predominant $r-K$ strategy in the microbial community (Blagodatsky et al., 1994). The parameters of MichaelisMenten kinetics are determined from experimentally measured relationships between the concentration of added glucose as respiration substrate and the short-term rate of soil $\mathrm{CO}_{2}$ efflux. Glucose is widely used to determine the parameters of microbial growth and microbial biomass in soil since it is one of the primary $\mathrm{C}$ substrates released into soil by rhizodeposition, as well as decomposition of cellulose and hemicellulose which are the most abundant constituents of plant residues and microbial cell walls (Paul and Clark, 1996).

Sikora and McCoy (1992) modified the Michaelis-Menten equation by adding a new parameter, AC, or a concentration of available carbon in soil. In some studies the proposed parameter is termed "content of native substrate", or $S_{n}$ (Panikov et al., 1992; Blagodatsky et al., 1994):

$v=\frac{\mathrm{V}_{\max } \times\left(S+S_{n}\right)}{K_{s}+S+S_{n}}$

Unlike the half-saturation Michaelis constant, $K_{S}$ is an integrated parameter. $K_{m}$ is the characteristic of an enzyme, while $K_{S}$ reflects the affinity of microbial cells towards a substrate. $S_{n}$ is equivalent to the added glucose concentration at zero $\mathrm{CO}_{2}$ efflux, i.e. the negative substrate concentration when respiration is extrapolated to zero. Available carbon, or native substrate, turns over within several hours (Panikov et al., 1992), i.e. much faster than labile SOM pool fitted by the single or double exponential decay function (Kätterer et al., 1998; MacDonald et al., 1995). However, both parameters describe the activity of soil microorganisms decomposing SOM.

As $S_{n}$ is very short-lived substrate, both substrate content and turnover should be taken into account. Turnover time $\left(T_{t}\right)$ of native endogenous substrate is determined as follows:

$T_{t}=\frac{K_{s}+S_{n}}{\mathrm{~V}_{\max }}$

Our research aimed to test the hypothesis of Davidson et al. (2006) using the modified Michaelis-Menten approach. To investigate the significance of the canceling effect, we performed $2 \mathrm{mo}$ soil incubations at $12^{\circ} \mathrm{C}$ and $22^{\circ} \mathrm{C}$. The parameters of glucose utilization were measured in soils taken from arable land depleted in SOM and forest site with high SOM content. In parallel, we monitored soil $\mathrm{CO}_{2}$ efflux in the long term 12 mo incubation for determining rate constants of SOM decomposition by a double exponential decay equation.

\section{Materials and methods}

\subsection{Site description and experimental design}

We used soil (Luvic Phaeozem) collected from two sites, forest and arable, situated $4 \mathrm{~km}$ to the west of Pushchino, Moscow Region, Russia $\left(54^{\circ} 50^{\prime} \mathrm{N}, 37^{\circ} 35^{\prime} \mathrm{E}\right)$.

The forest soil (0-20 cm; $\mathrm{C}_{\text {org }} 2.4 \%, \mathrm{pH}$ 5.6) was sampled randomly in late October, 2005 in a secondary mixed aspenlime-birch forest rich in herbs, with a mean tree age of 40-50 years. This site has been under forest for about 100 years. Soil samples from the arable site $\left(0-20 \mathrm{~cm} ; \mathrm{C}_{\text {org }} 1.0 \%, \mathrm{pH}\right.$ 6.5) were collected in late September 2005 after winter wheat harvest from unfertilized plot of a field experiment ( $9 \mathrm{yr}$ cereal rotation) established in the Field experimental station of the Institute of Physicochemical and Biological Problems in Soil Science RAS.

Freshly sampled soil was sieved through $3 \mathrm{~mm}$ mesh, followed by removal of fine roots with forceps. Then $50 \mathrm{~g}$ rootfree soil samples were placed into $500 \mathrm{ml}$ flasks and adjusted to $70 \%$ of water holding capacity (WHC). To test if the pattern of respiration fit to modified Michaelis-Menten kinetics increasing glucose concentration was added to fresh soil samples. Respiration response to substrate addition was measured at $22^{\circ} \mathrm{C}$. One day after soil collection the flasks with the soil were placed in two chambers adjusted to the temperatures $12^{\circ} \mathrm{C}$ and $22^{\circ} \mathrm{C}$, and incubated for over 2 months with weekly addition of deionised water so as to maintain moisture at a level of 70\% WHC. After this incubation, glucose solution was added to each sample to determine the kinetic parameters of substrate utilization by soil microorganisms. Parameters of microbial growth were determined one day later.

Respiration response of the soil samples to the addition of increasing concentrations of C- substrate (glucose, at the rates of $10-1000 \mu \mathrm{g} \mathrm{Cg}^{-1}$ dry soil) was measured within 30 min after the substrate addition and simulated by Eq. (2) (Sikora and McCoy, 1990; Panikov et al., 1992; Bradley and Fyles, 1996).

$\mathrm{CO}_{2}$ production by soil amended with glucose at the rate of $4 \mathrm{mg} \mathrm{Cg}^{-1}$ dry soil, providing substrate sufficient for unlimited microbial growth, was determined in the soil samples incubated at $22^{\circ} \mathrm{C}$ and $12^{\circ} \mathrm{C}$. Gas probes were sampled periodically, after $30 \mathrm{~min}$ incubation of the soil samples with tightly sealed lids. After gas sampling the flasks with soil were ventilated until the next gas sampling.

Glucose with mineral NPK salts was used to determine both the growth rate and the parameters of Michaelis-Menten 
kinetics (Blagodatsky et al., 2000). Concentrations of all solutions were adjusted to $\mathrm{C}: \mathrm{N}=10$ and $\mathrm{N}: \mathrm{P}: \mathrm{K}$ equal to $10: 5: 1$. Volumes of the added solutions were calculated to adjust the soil water content in the samples to $80 \%$ of water holding capacity.

In parallel, a long term 12 mo incubation was performed for determining the rate constants of SOM decomposition by a double exponential decay equation. To avoid the inhibition of soil respiration by high concentrations of $\mathrm{CO}_{2}$ respired, headspace $\mathrm{CO}_{2}$ concentrations were kept below $1.5 \%$. $\mathrm{CO}_{2}$ concentrations were determined 2-3 times a week during the first month of the incubation. At the advanced stages of the decomposition the interval was increased to 12 weeks. The flasks were ventilated for $30 \mathrm{~min}$ after each gas sampling.

The amount of $\mathrm{CO}_{2}$ increase in the incubation flasks was measured by gas chromatography. Concentration of $\mathrm{CO}_{2}$ in the headspace gas probes was analyzed on Chrom- 5 gas chromatograph on $2.5 \mathrm{~m}$ column with Porapack-Q using TCD. Carbon and nitrogen content in soil was measured by CHNanalyzer (Carlo Erba, Italy). Parameters of microbial growth and substrate utilization were measured in 5 replicates and the results of soil respiration during 12 mo incubation were obtained in 3-4 replicates. All results are expressed on an oven-dry weight basis.

\subsection{Determination of kinetic parameters}

Determination of the microbial growth rate involves simulation of the transition process of soil microorganisms from sustaining to an actively growing state, i.e. lag phase, as well as exponential phase of microbial growth after the addition of the excess quantities of a readily decomposable $\mathrm{C}$ substrate (Panikov and Sizova, 1996; Blagodatsky et al., 2000):

$v(t)=v_{u}+v_{c} \times e^{\mu_{\max } t}$

where $v(t)$ is $\mathrm{CO}_{2}$ production rate, $t$ is time, $v_{c}$ is the coupled respiration rate, $v_{u}$ is the uncoupled respiration rate, and $\mu_{\max }$ is the maximal specific growth rate when the microbial growth is unlimited.

Cumulative microbial respiration curves were fit to a double exponential decay model:

$Y=1-A_{0} e^{-k_{1} t}-\left(1-A_{o}\right) e^{-k_{2} t}$

where $Y$ is the cumulative amount of $\mathrm{C}-\mathrm{CO}_{2}$ at time $t$ expressed as a portion of organic $\mathrm{C}$ in soil, $A_{0}$ is a portion of labile pool, $k_{1}$ and $k_{2}$ are rate constants for labile and stable pools of organic matter, respectively.

All equations were fitted using nonlinear least-squares regression by the Marquardt algorithm. Since the difference between two incubation temperatures was equal to $10^{\circ} \mathrm{C}$, $\mathrm{Q}_{10}$ s were calculated as the ratio between the parameter values at $22^{\circ} \mathrm{C}$ and $12^{\circ} \mathrm{C}$.

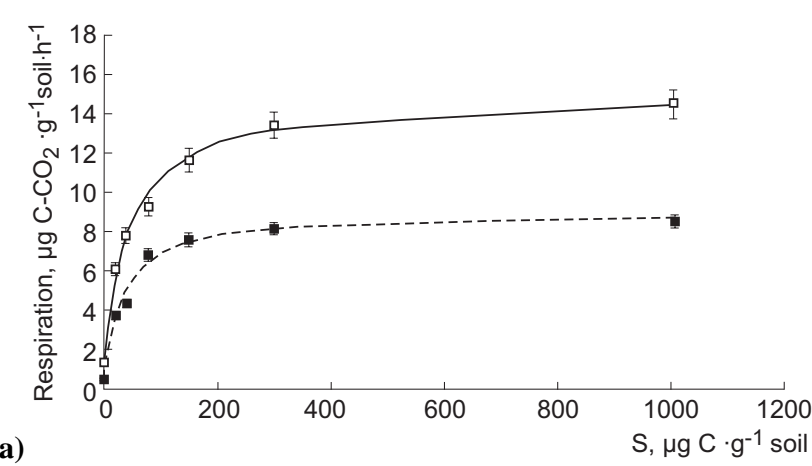

(a)

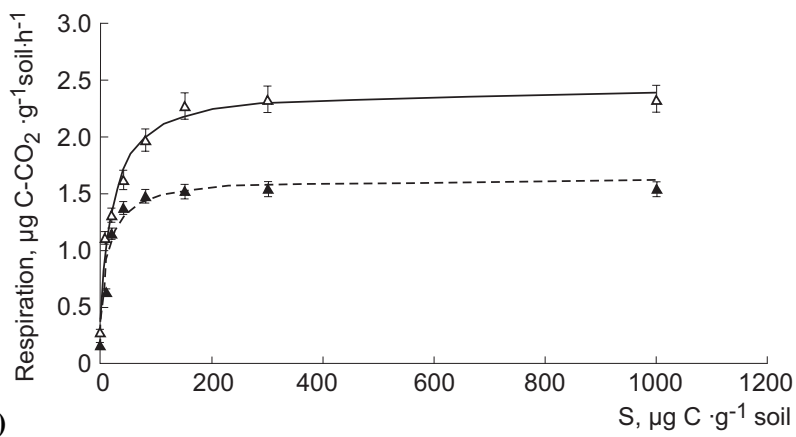

Fig. 1. Forest (a) and arable (b) soil respiration response to increasing concentration of added glucose determined at $22^{\circ} \mathrm{C}$ (solid line) and $12^{\circ} \mathrm{C}$ (dashed line) approximated by Eq. (2) $\left(R^{2}=0.95-0.99\right)$. Error bars indicate standard deviations, $n=5$.

\section{Results}

Parameters of glucose utilization were calculated by the modified Michaelis-Menten equation Eq. (2) with a good fit between measured and simulated data (Fig. 1). These parameters were time-, site- and temperature-dependent (Table 1).

$\mathrm{V}_{\max }, K_{s}$ and $S_{n}$ declined in the following order: forest soil at $22^{\circ} \mathrm{C}>$ forest soil at $12^{\circ} \mathrm{C}>$ arable soil at $22^{\circ} \mathrm{C}>$ arable soil at $12^{\circ} \mathrm{C}$. The decrease of glucose utilization parameters in unfavorable environments was associated with SOM depletion and temperature decrease (Table 1). Both $\mathrm{V}_{\max }$ and $K_{S}$ were higher at $22^{\circ} \mathrm{C}$ than at $12^{\circ} \mathrm{C}$ in the forest and arable soil (Table 1) canceling the increase of each other.

Less significant parameter changes were observed during the 2 mo incubation. The incubation resulted in the decrease of a readily decomposable native substrate $\left(S_{n}\right)$ in the forest soil, while in the arable soil all the parameters were unchanged. Turnover of $S_{n}$ was not temperature dependent, however it changed significantly during soil incubation: it slowed in arable soil and intensified in forest soil.

Microbial growth on excess glucose was simulated by Eq. (4) (Fig. 2). Maximal specific growth rate $\left(\mu_{\max }\right)$ obtained at the exponential phase of microbial growth was much higher at $22^{\circ} \mathrm{C}$ than at $12^{\circ} \mathrm{C}$, with $\mathrm{Q}_{10}$ values greater than 2 (Table 1). On the contrary, the values of $\mathrm{V}_{\max }$ fitted at the lag phase showed lower temperature response: the ratios 
Table 1. Parameter values of substrate utilization kinetics after glucose addition to the soil before and after 2 mo incubation. Values in parenthesis indicate standard error of the parameter.

\begin{tabular}{|c|c|c|c|c|c|c|c|c|}
\hline \multirow[b]{2}{*}{ Temperature ${ }^{\circ} \mathrm{C}$} & \multirow{2}{*}{$\begin{array}{c}\text { Initial sample } \\
22\end{array}$} & \multicolumn{2}{|c|}{ Sample after incubation } & \multirow[b]{2}{*}{$\mathrm{Q}_{10}$} & \multirow{2}{*}{$\begin{array}{c}\text { Initial sample } \\
22\end{array}$} & \multicolumn{2}{|c|}{ Sample after incubation } & \multirow[b]{2}{*}{$\mathrm{Q}_{10}$} \\
\hline & & 22 & 12 & & & 22 & 12 & \\
\hline & \multicolumn{3}{|c|}{ forest soil } & \multicolumn{5}{|c|}{ arable soil } \\
\hline $\mathrm{V}_{\max }, \mu \mathrm{gC}-\mathrm{CO}_{2} \mathrm{~g}^{-1} \mathrm{~h}^{-1}$ & $15.6(0.5)$ & $15.1(0.4)$ & $9.1(0.3)$ & 1.7 & $2.9(0.3)$ & $2.4(0.2)$ & $1.6(0.1)$ & 1.5 \\
\hline$K_{S}, \mu \mathrm{g} \mathrm{Cg}^{-1}$ & $50.6(6.8)$ & $43.0(5.2)$ & $33.3(3.8)$ & 1.3 & $12.2(1.3)$ & $18.0(2.7)$ & $11.4(1.6)$ & 1.6 \\
\hline$S_{n}, \mu \mathrm{g} \mathrm{Cg}^{-1}$ & $10.8(2.4)$ & $5.2(1.1)$ & $2.2(0.8)$ & 2.4 & $1.8(0.8)$ & $2.7(0.8)$ & $1.1(0.3)$ & 2.4 \\
\hline$T_{t} \mathrm{~h}$ & $6.6(1.3)$ & $3.2(0.7)$ & $3.9(0.8)$ & 0.8 & $4.8(1.0)$ & $8.5(2.2)$ & $7.7(1.9)$ & 1.1 \\
\hline$\mu_{\max }, \mathrm{h}^{-1}$ & $\mathrm{Nd}$ & $0.29(0.02)$ & $0.14(0.01)$ & 2.1 & nd & $0.14(0.01)$ & $0.07(0.01)$ & 2.0 \\
\hline
\end{tabular}

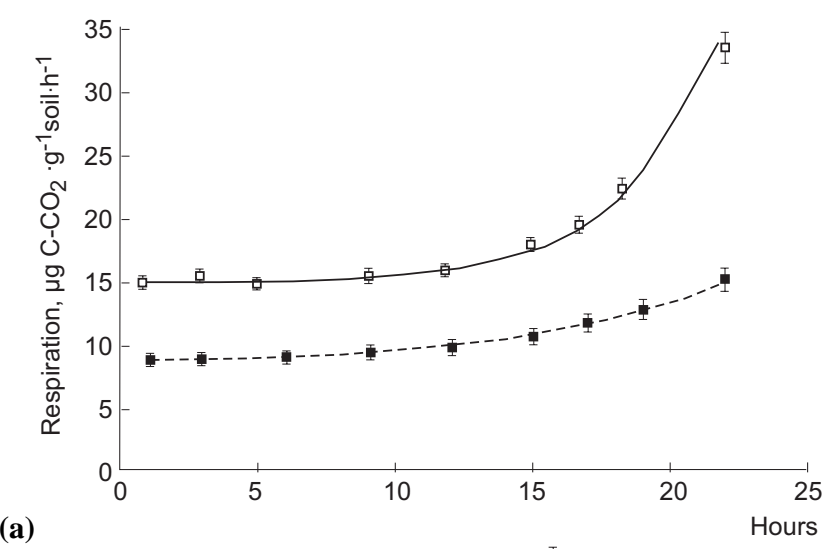

(a)

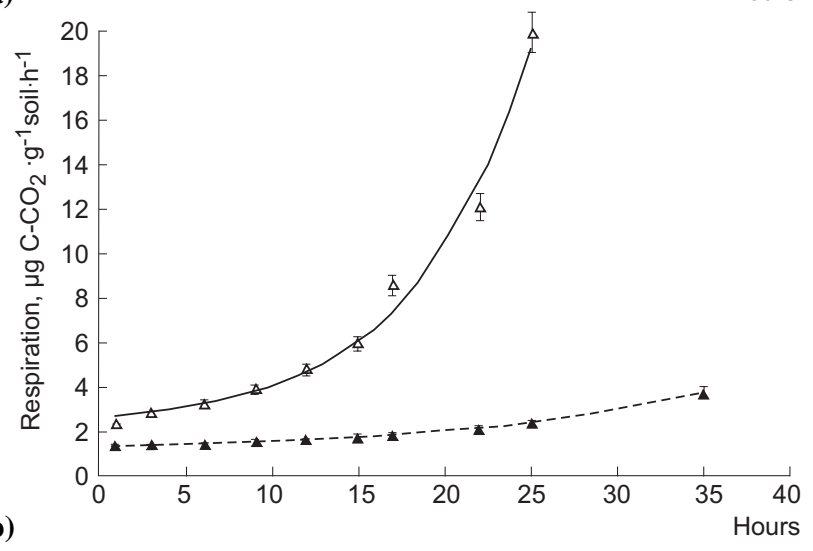

Fig. 2. Dynamics of forest (a) and arable (b) soil respiration amended with glucose excess $\left(4 \mathrm{mg} \mathrm{Cg}^{-1}\right.$ soil) in response to incubation temperature: $22^{\circ} \mathrm{C}$ (solid line) and $12^{\circ} \mathrm{C}$ (dashed line) simulated by Eq. (4) $\left(R^{2}=0.93-0.98\right)$. Error bars indicate standard deviations, $n=5$.

between $\mathrm{V}_{\max }$ at $22^{\circ} \mathrm{C}$ and $12^{\circ} \mathrm{C}$ were 1.7 and 1.5 for the forest and arable soils, respectively. These $\mathrm{Q}_{10} \mathrm{~s}$ of $\mathrm{V}_{\max }$ were lower than the value of 2 assigned by Davidson et al. (2006). $\mathrm{Q}_{10} \mathrm{~s}$ of $\mathrm{V}_{\max }$ obtained in our experiment were also lower than the temperature coefficients of $S_{n}$.
Hence, temperature response of soil respiration changes with substrate concentration (Table 1): it is the highest at zero glucose addition with the decomposition of endogenous substrate, decreases significantly at high glucose concentrations, providing unlimited microbial respiration $\mathrm{V}_{\max }$, and increases again during $24 \mathrm{~h}$ substrate unlimited microbial growth.

Cumulative soil respiration during annual incubation fit well to the double exponential decay function Eq. (2); $R^{2}=0.99$. Soil respiration, rate constants and the size of labile pool were higher in the forest soil reflecting depletion of total and labile SOM in the arable land (Table 2). All the fitted parameters were significantly related to the temperature. The rate constants $k_{2}$ were much more sensitive to the temperature than $k_{1}$ for both soils. Temperature elevation increased the rate constants and the size of labile SOM pool as well (Table 2). The size of respirable labile $\mathrm{C}$ pool $\left(A_{0}\right)$ was 1.3-3.4 times higher at $22^{\circ} \mathrm{C}$ than at $12^{\circ} \mathrm{C}$.

\section{Discussion}

4.1 Parameters of microbial growth and substrate utilization

The covariation of $\mathrm{V}_{\max }$ and $K_{s}$ with temperature confirms the importance of the canceling effect suggested by Davidson et al. (2006). The canceling effect is significant when substrate concentration is lower or close to $K_{s}$.If substrate concentration is much higher than $K_{s}$, the temperature response of substrate affinity becomes insignificant. We determined the parameters of the modified Michaelis-Menten equation Eq. (2) at the start of the experiment and after 2 mo incubation (Table 1). $S_{n}$ values both in forest and arable soils were lower than $K_{s}$ value at any measurement time or incubation temperature. The values of $S_{n}$ for arable soils obtained by Sikora and McCoy (1990) and Badalucco and Hopkins (1997) in short-term incubations were equal to $K_{s}$, supporting the hypothesis of the canceling effect in soils. In almost all ecosystems, the availability of carbon and 
Table 2. Parameter values of microbial respiration by the decomposition of soil organic matter $\left(k_{1}\right.$ and $k_{2}$ rate constants of labile and recalcitrant pools, $A_{o}$ - pool size of labile substrate). Values in parenthesis indicate standard error of the parameter.

\begin{tabular}{lcccccc}
\hline Temperature ${ }^{\circ} \mathrm{C}$ & 12 & 22 & $\mathrm{Q}_{10}$ & 12 & 22 & $\mathrm{Q}_{10}$ \\
\hline & & forest soil & & & arable soil \\
\hline$A_{o}\left(\times 10^{-2}\right)$ & $2.1(0.03)$ & $3.1(0.12)$ & 1.5 & $0.64(0.08)$ & $2.2(0.10)$ & 3.4 \\
$k_{1}$, day $^{-1}\left(\times 10^{-2}\right)$ & $2.1(0.07)$ & $1.8(0.15)$ & 0.9 & $1.6(0.27)$ & $2.1(0.24)$ & 1.3 \\
$k_{2}$, days $^{-1}\left(\times 10^{-4}\right)$ & $0.62(0.01)$ & $1.4(0.05)$ & 2.3 & $0.72(0.03)$ & $1.9(0.04)$ & 2.6 \\
\hline
\end{tabular}

energy sources are extremely restricted (Morita, 1988), and the canceling effect can be an important factor controlling apparent temperature acclimation across soil types.

When $\mathrm{V}_{\max }$ and $K_{S}$ cancel each other, respiration is controlled by SOM decomposition producing available substrate $\left(S_{n}\right)$ (Ågren and Wetterstedt, 2007). The enlargement of $S_{n}$ at higher temperature (Table 1) indicates an increase in the enzymatic activity stimulating decomposition of recalcitrant SOM. The combination of temperature dependent $S_{n}$ release into the soil with canceling effect explains $\mathrm{Q}_{10}$ changes at increased rates of glucose addition. The highest temperature response of soil respiration was found in the arable and forest soils at a low substrate concentration. $\mathrm{Q}_{10} \mathrm{~s}$ of respiration rates with no glucose added $(S=0)$ were consistent with $\mathrm{Q}_{10} \mathrm{~S}$ of $S_{n}$ (Fig. 1, Table 1). After glucose addition, the effect of $S_{n}$ differences becomes insignificant, since glucose input ranged from $10-1000 \mu \mathrm{g} \mathrm{Cg}^{-1}$ dry soil, while $S_{n}$ was as low as 1$5 \mu \mathrm{g} \mathrm{Cg}^{-1}$ dry soil (Table 1). As substrate supply increased to the $K_{s}$ values, which are in the range of $10-50 \mu \mathrm{g} \mathrm{Cg}^{-1}$ dry soil (Table 1), the canceling effect was the main controlling factor of soil respiration. When the substrate concentration does not limit microbial respiration by substrate input of $500-1000 \mu \mathrm{g} \mathrm{Cg}^{-1}$ dry soil, i.e. much higher than $K_{s}$, the canceling effect was not important.

At high substrate content when microbial respiration is unlimited, the whole microbial community demonstrated low temperature response, while its growing component showed higher temperature sensitivity. $\mathrm{Q}_{10} \mathrm{~s}$ of $\mu_{\max }$ describing growing microbial biomass were higher than those of $\mathrm{V}_{\max }$ reflecting respiratory response of the whole microbial community (Table 1). The fact that microbial growth is more temperature sensitive than maintenance has been confirmed by the response of soil microorganisms to extremely low temperatures (Panikov et al., 2006). No microbial growth was found at temperatures below $0^{\circ} \mathrm{C}$, while maintenance respiration was detected at the temperature as low as $-39^{\circ} \mathrm{C}$.

Microbial biomass partitioning on growing and sustaining (active, but not growing) components (Blagodatsky et al., 2000) showed that the growing component amounts to only $10-20 \%$ of total biomass. As the total microbial community and its growing component exhibited different temperature responses (Table 1), the increase in growing biomass, e.g. from 10 to $20 \%$ can also contribute to temperature sensitivity changes of soil respiration. The reverse shifts from growing to sustaining and dormant physiological states also can alter respiration dependence on soil temperature. Therefore temperature sensitivity correlated with the glucose decomposition rate in a long-term soil incubation with added labeled glucose (Nicolardot et al., 1994): the highest temperature sensitivity was observed at the first stages of the experiment when glucose decomposition rate was the highest. After the added glucose was depleted, and proportion of sustaining biomass increased, the temperature sensitivity decreased significantly.

Our results (Fig. 1, Table 1) illustrate two types i) temperature dependent $\left(S_{n}\right)$ and ii) temperature independent $(S)$ supply of readily decomposable substrate to the soil. The canceling effect plays a very important role when the substrate input is not temperature dependent, while response of substrate production to temperature changes becomes the main controlling factor in situations where only endogenous substrate is present in soil. When substrate concentration does not limit soil respiration, temperature response depends on the temperature sensitivity of microbial growth and the portion of growing component in the total microbial biomass.

The changes in glucose utilization parameters associated with temperature alterations can reflect real physiological temperature adaptations of soil microorganisms as well as the apparent acclimation caused by changes in substrate concentration and quality. It is often impossible to differentiate real and apparent acclimation since both respiration and substrate availability change along with temperature (Kirschbaum, 2006). Since the $S_{n}$ values determined in our experiment were temperature dependent, we also could not differentiate the real and apparent acclimation (Table 1).

This study is the first attempt to experimentally verify the canceling effect hypothesis. We have presented the results of long-term ( $2 \mathrm{mo}$ ) incubation. The question of whether the canceling effect is important during short -term temperature changes is still unanswered.

Taking into account the ability of soil microbial biomass to modulate kinetic properties according to the growth environment, the time scale of such an adaptive response becomes of great interest. Both steady state (Giardina and Ryan, 2000; 
Ise and Moorcraft, 2006) and transient (Eliasson et al., 2005) lowering of temperature responses are found in C models. If the time delay between $\mathrm{V}_{\max }$ and $K_{S}$ changes is significant, the canceling effect would be short-lived, while synchronous alterations of these parameters lead to the $\mathrm{V}_{\max }$ and $K_{S}$ canceling in the long-term.

In the present study we discussed the temperature responses of kinetic parameters when a single compound (glucose) is controlling microbial respiration. In contrast to the laboratory, microorganisms in soils grow with complex mixtures of substrates. Usually all of them are at very low concentrations (Kalbitz et al., 2003) with the exception of litter fall season when the substrate supply is more abundant. An improved substrate affinity (decreased $K_{s}$ ) of the individual compounds was found during microbial growth with a substrate mixture (Kovárová-Kovar and Egli, 1998). The values of kinetic parameters are also limited by nutrients. The optimization of the experimental procedure by which the parameters of microbial growth (Eq. 4) are determined evidence that $\mu_{\max }$ was higher in glucose+NPK treatment than in glucose-only amendment (Blagodatsky et al., 2000). Therefore experimental confirmation of the kinetic interaction of non-homologous $\mathrm{C}$ and $\mathrm{N}$ substrates with changing temperature is required.

\subsection{Temperature response of labile and recalcitrant SOM}

These results support the hypothesis that low-quality substrates (i.e. substrates with a low proportion of readily decomposable $\mathrm{C}$ substances) are mineralized with a higher $\mathrm{Q}_{10}$ than labile substrates (Bosatta and Ågren, 1999; Knorr et al., 2005; Leifeld and Fuhrer, 2005; Waldrop and Firestone, 2004; Fierer et al., 2006). The majority of methodological approaches, including our long-term incubation, estimate the response of two small SOM pools with mean residence times of years and decades. Both pools can be considered labile compared to the old SOM pool, with turnover times of centuries and millennia. The sensitivity of this old stable SOM to soil warming was found to be higher than the response of labile SOM as well (Leifeld and Fuhrer, 2005), although the approach used for separation of stable SOM is destructive. Harsh treatment with $\mathrm{HCl}$ would increase microbial access to physically protected SOM, i.e. improve the quality of decomposing substrate. Hence, the temperature sensitivity of old SOM in natural conditions is still unknown.

A number of studies reported that the temperature response may not correlate (Dioumaeva et al., 2003; Fang et al., 2005; Reichstein et al., 2005a; Conen et al., 2006) or correlate positively (Liski, 1999; Giardina and Ryan, 2000; Mellilo et al., 2002) with SOM quality. Positive correlation contradicts the kinetic theory, which indicates higher temperature sensitivity for the decomposition of stable SOM (Bosatta and Ågren, 1999; Davidson and Janssens, 2006), and the conclusion about its low temperature sensitivity is often based on incorrect assumptions. Temperature insensi- tivity of old SOM in Liski's model (Liski, 1999) is the consequence of an assumption about fixed mean residence time of soil C pools (Ågren, 2000). The analysis of geographical trend in Giardina and Ryan's study takes into account the decomposition of only one homogenous SOM pool, while the decomposition rate depends on the abundance of SOM pools with different kinetic characteristics (Davidson and Janssens, 2006). Multipool models of SOM decomposition (Eliasson et al., 2005; Kirschbaum, 2004) have demonstrated good fit with data obtained in soil warming experiments. In these experiments the initial flush of decomposition disappears in a few years (Mellilo et al., 2002; Eliasson et al., 2005), and temperature insensitivity of recalcitrant SOM is suggested to explain this phenomenon (Mellilo et al., 2002). However, the initial SOM loss can be attributed to decomposition of rapidly cycling pools, while in the longer term more recalcitrant decadally cycling pools continue to loose $\mathrm{SOM} . \mathrm{CO}_{2}$ efflux produced by the decomposition of these recalcitrant pools is hardly detectable as it contributes less than 5\% increase in total soil respiration in a several years of soil warming (Trumbore, 2006).

Modeling of the fixed labile pool (Parton et al., 1987; Kätterer et al., 1998) simulated at the highest incubation temperature $30-35^{\circ} \mathrm{C}$ suggested that temperature changes affect the rate constant only. However, the assumption of constant pool size may be incorrect (MacDonald et al., 1995; Waldrop and Firestone, 2004). The enlargement of the labile pool at higher temperature indicates an increase in the enzymatic activity stimulating decomposition of recalcitrant SOM. There are two main groups of extracellular enzymes produced by soil microorganisms decomposing macromolecular SOM: oxidative and hydrolytic enzymes. The first group is involved in the conversion of phenolic polymers into labile compounds while the second is used to decompose cellulose. Enhanced oxidative enzyme activity in response to the elevated temperature was proposed as the mechanism providing greater microbial access to the recalcitrant SOM and, therefore, resulting in an increased labile SOM pool (Waldrop and Firestone, 2004). This mechanism can compensate for the labile substrate depletion at elevated temperatures. At high temperature, the decrease in respiration rate caused by the depletion of readily available substrate is followed by the increase in the initial rate of SOM decomposition. The same mechanism is proposed as the explanation for the apparent acclimation in experiments with soil warming or long-term incubation (Eliasson et al., 2005; Kirschbaum, 2006). However, the increase of both $S_{n}$ (Table 1) and the labile SOM pool $A_{0}$ (Table 2) due to temperature elevation found in our experiments indicates that no substrate depletion happened. Conversely, lower substrate content was detected at the lower temperature of $12^{\circ} \mathrm{C}$. Compensation of the respired labile SOM occurred in both soils studied, with more prominent increase of $A_{0}$ in arable soil (Table 2). Thus, our data suggest the importance of a feedback between substrate depletion and microbial access to recalcitrant SOM. 
Both methodological approaches used in our experiments gave similar indices of labile C: the $S_{n}$ determined by modified Michaelis-Menten equation is consistent with $A_{0}$ simulated by double exponential decay model. Higher $S_{n}$ values at $22^{\circ} \mathrm{C}$ correspond well to the increased labile pool $A_{0}$ at this temperature (Tables 1 and 2) compared to $12^{\circ} \mathrm{C}$. The parameters of the Michaelis-Menten equation are more informative for understanding apparent acclimation and variability of temperature sensitivity as a function of high quality substrate concentration. As mentioned, the canceling effect is significant when the concentration of readily decomposable substrate is lower or comparable to the $K_{s}$ concentration by SOM degradation.

When the pool of recalcitrant and stable SOM is being decomposed, the level of $S_{n}$ is much lower than $K_{s}$, and $S_{n}$ release into the soil is temperature dependent. Therefore two factors: i) the canceling effect and ii) the rate by which SOM is decomposed to substrates available for microorganisms control temperature response of soil respiration.

In the contrast to the temperature response, the labile pools $S_{n}$ and $A_{0}$ were not in good agreement during soil incubation in which the decrease of both pools was expected. In the forest soil the intensification of $S_{n}$ turnover was detected with decreasing of both substrate content and turnover time, while in the arable soil more intensive $S_{n}$ turnover was observed at the start of incubation, and $S_{n}$ did not change significantly with time (Table 1). It remains an open question whether the revealed changes of $S_{n}$ and $T_{t}$ reflect reality or are just a result of soil disturbance. The effect of soil mixing during sample preparation on kinetic parameters should be elucidated to obtain environmentally relevant sizes of carbon pools and characteristics of microbial growth and substrate utilization.

This study is the starting point to assess biologically and ecologically meaningful parameters $\mathrm{V}_{\max }, K_{s}, S_{n}$, which are necessary to determine respiration responses to changing temperature. Since we can not derive these parameters from individual studies on SOM decomposition, the determination of these parameters at the early and advanced stages of decomposition over a broad range of temperatures in a wide variety of soils would be useful for modeling of transient and steady state effects of temperature responses by SOM decomposition. Our results have limited implications for natural conditions. We suggest that the canceling effect is more important in field experiments than in our laboratory incubations when the release of easily decomposable substrate into the soil is temperature independent. Such temperature insensitive processes as seasonal litter fall and drying-rewetting events that are usually considered as confounding factors (Kirschbaum, 2006; Reichstein et al., 2005b) can substantially increase $S_{n}$ values at high or low temperature. At the same time temperature sensitive SOM decomposition affects soil respiration as well. The combination of temperature dependent and independent processes resulting in $S_{n}$ production is the main reason for unstable temperature sensitivity of soil respiration in the field conditions.

Our results confirmed the significance of the canceling effect as well as the rate of substrate release into the soil and shift in physiological state of soil microorganisms. The experimental testing of other factors modifying kinetic parameters and temperature response of soil respiration, e.g. microbial growth with substrates mixture versus single compound, effect of nutrients, asynchronous parameter changes etc., is required. The search for unknown combinations of processes which result in non-trivial temperature response of SOM decomposition will improve our understanding of $\mathrm{C}$ cycle in ecosystems.

\section{Conclusions}

Our data suggest that the parameters of microbial growth and substrate utilization are useful for the explanation of the temperature dependence of soil respiration on the concentration of readily decomposable substrate. The temperature response of SOM decomposition is the highest when the substrate concentration is very low $\left(S+S_{n} \ll K_{S}\right)$. During the decomposition of endogenous substrate $(S=0)$ soil respiration is governed by two factors $\mathrm{i}$ ) the canceling effect of $\mathrm{V}_{\max }$ and $K_{s}$ temperature sensitivities and ii) temperature dependent release of native substrate $\left(S_{n}\right)$ by SOM decomposition. As substrate content increases to the $K_{s}$ values $\left(S+S_{n}=K_{s}\right)$, the canceling effect is of great importance as a primary mechanism of apparent acclimation, i.e. substantial lowering of the temperature sensitivity of microbial respiration. Temperature sensitivity of $S_{n}$ production is not important, since $S_{n}$ is much lower than $K_{s}$. When the substrate concentration does not limit microbial respiration $\left(S+S_{n} \gg K_{S}\right)$, soil $\mathrm{CO}_{2}$ efflux is close to $\mathrm{V}_{\max }$, and both the canceling effect and $S_{n}$ release have minor importance. Temperature response of substrate-unlimited respiration depends on the portion of growing microbial biomass in the total microbial $\mathrm{C}$ pool: the larger the growing biomass pool is, the higher the temperature sensitivity of microbial respiration detected. The approach used in this work improves our understanding of the effect of both temperature dependent and independent substrate release into the soil, which are usually considered confounding factors controlling the response of $\mathrm{CO}_{2}$ efflux to soil warming.

Acknowledgements. This research was supported by the Russian Foundation for Basic Research (projects 05-04-48441, 06-0448756, 06-04-90610), Program "Russian Scientific Schools" (grant NS 3096.2006.4) and the Russian Academy of Sciences (program 16). We are grateful to M. B. Leigh for the revision and improvement of English in the text of manuscript.

Edited by: J. Leifeld 


\section{References}

Ågren, G.: Temperature dependence of old soil organic matter, Ambio, 29, p. 55, 2000.

Ågren, G. I and Wetterstedt, J. Å. M.: What determines the temperature response of soil organic matter decomposition?, Soil Biol. Biochem., 39, 1794-1798, 2007.

Badalucco, L. and Hopkins, D. W.: Available carbon in soil determined from substrate utilization kinetics: comparison of substrates and soil amendments, J. Microbiol. Methods, 30, 43-47, 1997.

Blagodatsky, S. A., Blagodatskaya, E. V., and Rozanova, L. N.: Kinetics and strategy of microbial growth in Chernozemic soil affected by different long-term fertilization, Microbiology, 63, 298-307, 1994.

Blagodatsky, S. A., Heinemeyer, O., and Richter, J.: Estimating the active and total soil microbial biomass by kinetic respiration analysis, Biol. Fertil. Soils, 32, 73-81, 2000.

Bosatta, E. and Ågren, G. I.: Soil organic matter quality interpreted thermodynamically, Soil Biol. Biochem., 31, 1889-1891, 1999.

Bradley, R. L. and Fyles, J. W.: A kinetic parameters describing soil available carbon and its relationship to rate increase in $\mathrm{C}$ mineralization, Soil Biol. Biochem., 27, 167-172, 1995.

Conen, F., Leifeld, J., Seth, B., and Alewell, C.: Warming mineralises young and old soil carbon equally, Biogeosciences, 3, 515-519, 2006, http://www.biogeosciences.net/3/515/2006/.

Davidson, E. A., Janssens, I. A., and Luo, Y.: On the variability of respiration in terrestrial ecosystems: moving beyond $\mathrm{Q}_{10}$, Global Change Biol., 12, 154-164, 2006.

Davidson, E. A. and Janssens, I. A.: Temperature sensitivity of soil carbon decomposition and feedbacks to climate change, Nature, 440, 165-173, doi:10.1038/nature04514, 2006.

Dioumaeva, I., Trumbore, S., Schnur, E. A. G., Goulden, M. L., Litvak, M., and Hirsch, A. I.: Decomposition of peat from upland boreal forest: Temperature dependence and sources of respired carbon, J. Geophys. Res., 108(D3), 8222, doi:10.1029/2001JD000848, 2003.

Eliasson, P. E., McMutrtrie, R. E., Pepper, D. A., Strömgren, M., Linder, S., and Ågren, G. I.: The response of heterotrophic $\mathrm{CO}_{2}$ flux to soil warming, Global Change Biol., 11, 167-181, 2005.

Fang, C., Smith, P., Moncrieff, J., and Smith, J. U.: Similar response of labile and resistant soilorganic matter pools to changes in temperature, Nature, 433, 57-59, 2005.

Fierer, N., Colman, B. P., Schimel, J., and Jackson, R. B.: Predicting the temperature dependence of microbial respiration in soil: A continental scale analysis, Global Biogeochem. Cy., 20, GB3026, doi:10.1029/2005GB002644, 2006.

Giardina, N. P. and Ryan, M. G.: Evidence that decomposition rates of organic carbon in mineral soil do not vary with temperature, Nature, 404, 858-861, 2000.

Ise, T. and Moorcroft, P. R.: The global-scale temperature and moisture dependencies of soil organic carbon decomposition: an analysis using a mechanistic decomposition model, Biogeochemistry, 80, 217-231, 2006.

Kalbitz K., Schwesig D., Schmerwitz J., Kaiser K., Haumaier L., Glaser B., Ellerbock R., and Leinweber P.: changes in properties of soil-derived dissolved organic matter induced by biodegradation, Soil Biol. Biochem., 35, 1129-1142, 2003.

Kätterer, T., Reichstein, M., Andrén, O., and Lomander, A.: Tem- perature dependence of organic matter decomposition: a critical review using literature data analysed with different models, Biol. Fertil. Soils, 27, 258-262, 1998.

Kirschbaum, M. U. F.: Soil respiration under prolonged soil warming: are rate reductions caused by acclimation or substrate loss?, Global Change Biol., 10, 1870-1877, 2004.

Kirschbaum, M. U. F.: The temperature dependence of organic matter decomposition - still a topic of debate, Soil Biol. Biochem., 38, 2510-2518, 2006.

Knorr, W., Prentice, I. C., House, J. I., and Holland, E. A.: Longterm sensitivity of soil carbon turnover to warming, Nature, 433, 298-301, 2005.

Kovárová-Kovar K., and Egli T.: Growth kinetics of suspended microbial cells: from single-substrate-controlled growth to mixedsubstrate kinetics, Microbiol. Mol. Biol. Rev., 62, 646-666, 1998.

Leifeld, J. and Fuhrer, J.: The temperature response of $\mathrm{CO}_{2}$ production from bulk soils and soil fractions is related to soil organic matter quality, Biogeochemistry, 75, 433-453, 2005.

Liski, J., Ilvesniemi, H., Mäkelä, A., and Westman, K. J.: $\mathrm{CO}_{2}$ emissions from soil in response to climatic warming are overestimated - the decomposition of old soil organic matter is tolerant to temperature, Ambio, 28, 171-174, 1999.

MacDonald, N. W., Zak, D. R., and Pregitzer, K. S.: Temperature effect on kinetics of microbial respiration and net nitrogen and sulfur mineralization, Soil Sci. Soc. Amer. J., 59, 233-240, 1995.

Melillo, J. M., Steudler, P. A., Aber J. D., Newkirk, K., Lux, H., Bowles, F. P., Catricala, C., Magill, A., Ahrens, T., and Morrisseau, S.: Soil warming and carbon cycle feedbacks to the climate system, Science, 298, 2173-2176, 2002.

Morita, R. Y.: Bioavailability of energy and its relationship to growth and starvation survival in nature, J. Can. Microbiol., 43, 436-441, 1988.

Nicolardot, B., Fauvet, G., and Chenby, D.: Carbon and nitrogen cycling through soil microbial biomass at various temperatures, Soil Biol. Biochem., 26, 253-261, 1994.

Panikov, N. S., Blagodatsky, S. A., and Glagolev, M. V.: Determination of microbial mineralization activity in soil by modified Wright and Hobbie method, Biol. Fertil. Soils, 14, 280-287, 1992.

Panikov, N. S., Flanagan, P. W., Oechel, W. C., Mastepanov, M. A., and Christensen, T. R.: Microbial activity in soils frozen to below $-39^{\circ} \mathrm{C}$, Soil Biol. Biochem., 38, 785-794, 2006.

Panikov, N. S. and Sizova, M. V.: A kinetic method for estimating the biomass of microbial functional groups in soil, J. Microbiol. Methods, 24, 219-230, 1996.

Parton, W. J., Schimel, D. S., Cole, Ñ. V., and Ojima, D. S.: Analysis of factors controlling soil organic matter levels in Great Plains grasslands, Soil Sci. Society Amer. J., 51, 1173-1179, 1987.

Paul, E. A. and Clark, F. E.: Soil Microbiology and Biochemistry, 2nd ed., Academic Press, SanDiego, 273 pp., 1996.

Reichstein, M., Kätterer, T ., Andrén, O., Ciais, P., Schulze, E.-D., Cramer, W., Papale, D., and Valentini, R.: Temperature sensitivity of decomposition in relation to soil organic matter pools: critique and outlook, Biogeosciences, 2, 317-321, 2005a.

Reichstein, M., Subke, J.-A., Angeli, A., and Tenhunen, J. D.: Does the temperature sensitivity of decomposition of soil organic matter depend on water content, soil horizon, or incubation time?, Global Change Biol., 11, 1754-1767, 2005b. 
Sikora, L. J. and McCoy, J. L.: Attempts to determine available carbon in soils, Biol. Fertil. Soils, 9, 19-24, 1990.

Thornley, J. H. M. and Cannell, M. G. R.: Soil carbon storage response to temperature: an hypothesis, Annals Botany, 87, 591598, 2001.

Trumbore, S.: Carbon respired by terrestrial ecosystems - recent progress and challenges, Global Change Biol., 12, 141-153, 2006.
Waldrop, M. P. and Firestone, M. K.: Altered utilization patterns of young and old soil $\mathrm{C}$ by microorganisms caused by temperature shifts and N additions, Biogeochemistry, 67, 235-248, 2004. 